\title{
Effect of Electric Current on the Inclusions in a Cu-Zn Alloy
}

\author{
Wenbin Dai and Xinli Wang* \\ School of Materials and Metallurgy, Northeastern University, Shenyang 110004, P. R. China
}

The effect of electric current pulse (ECP) treatment on lead inclusions in a $\mathrm{Cu}-\mathrm{Zn}$ alloy was studied in present work. It was found that with the application of a critical high current density, the coarse and random distributed lead inclusions transferred into grain boundaries or defects in dispersed small particles. The reason was ascribed to the specific electric effect of electric current on the grain refinement and the reduction of the diffusive activation energy of lead inclusions. Therefore, the high current density ECP treatment might be an effective method to refine inclusions of bulk materials. [doi:10.2320/matertrans.M2009389]

(Received November 24, 2009; Accepted February 9, 2010; Published March 25, 2010)

Keywords: electric current pulse, inclusions, segregation, diffusion

\section{Introduction}

Electric current pulse (ECP) treatment as an important instantaneous nonequilibrium processing technique has been used in materials science and engineering field for several decades. The current research fields about ECP include: electromigration, ${ }^{1)}$ electroplastic, ${ }^{2)}$ the solidification of metals and alloys, ${ }^{3)}$ and so on. Recently, studies concerning grain refinement in conventional coarse-grained materials by applying high current density ECP treatment have achieved lots of significant results. ${ }^{4-6)}$ For example, Zhou et al. have found that grains in a low carbon steel are refined after high current density ECP treatment; ${ }^{4)}$ Zhang et al. have found that nanophases are formed in a conventional coarse-grained polycrystalline $\mathrm{Cu}-\mathrm{Zn}$ alloy by applying high current density ECP treatment. ${ }^{5)}$ It gives us an insight into whether the application of ECP treatment could refine the inclusions and make them homogeneously distribute. If it is possible, the mechanical properties of metallic materials might be greatly improved.

As known, the flow of electric current can give rise to mass transport and the segregation is closed with the diffusion of atoms. ${ }^{1)}$ Moreover, Zhou et al. have proposed that the diffusion of atoms, ${ }^{6}$ ) and the diffusive transformation could be accelerated properly due to the enhancement of diffusion coefficient under ECP treatment. However, though chemical segregation caused by conventional heat treatments has been studied for several years, ${ }^{7-9)}$ there are few reports about the segregation under high current density ECP treatment in bulk materials.

In present work, the effect of different current density ECP treatment on the distribution of lead inclusions in a $\mathrm{Cu}-\mathrm{Zn}$ alloy was investigated, and based on thermodynamic analysis, a possible segregation mechanism of lead inclusions under ECP was proposed.

\section{Experimental}

A commercial $\mathrm{Cu}-\mathrm{Zn}$ alloy sheet with a composition of $\mathrm{Cu}$ 59.1 mass \%, Zn 40.6 mass \%, and $\mathrm{Pb} 0.3$ mass \% was selected as the investigated material. The sheet was cold worked in

*Corresponding author, E-mail: wangx1520@hotmail.com thickness from 1.5 to $1.0 \mathrm{~mm}$ at room temperature by rolling. By using the electrospark discharge technique, the alloy sheet was cut into a required shape (the size of the middle part was $3 \mathrm{~mm}$ long, $2 \mathrm{~mm}$ wide, and $1 \mathrm{~mm}$ thick, and the size of the two ends of the sample was much larger than that of the middle part). Thus, the current density of the two ends was much less than that of the middle part during current passing. The ECP treatment was performed by capacitor banks discharge under ambient conditions with current densities at $18.0 \mathrm{kA} \cdot \mathrm{mm}^{-2}, \quad 18.6 \mathrm{kA} \cdot \mathrm{mm}^{-2}$, and $19.0 \mathrm{kA} \cdot \mathrm{mm}^{-2}$, respectively. Its waveform was detected to be a damped oscillation wave by a Rogowski coil and a TDS3012 digital storage oscilloscope (Tektronix Inc., Beaverton, OR). The period of ECP $\left(t_{\mathrm{p}}\right)$ was about $113 \mu \mathrm{s}$ and the pulse duration $\left(t_{\mathrm{d}}\right)$ was about $800 \mu \mathrm{s}$.

The morphology of effective parts was determined by a JSM-6301F JEOL field emission scanning electron microscope (SEM). To reveal the lead distribution, backscattered electron (BSE) in the SEM was utilized.

\section{Results}

Figure 1 shows SEM images of samples before and after ECP treatment. Due to previous cold rolling deformation, $\alpha$ and $\beta^{\prime}$ grains in the sample before ECP treatment are coarse and elongated (Fig. 1(a)). While in ECP treated samples with current densities at $18.0 \mathrm{kA} \cdot \mathrm{mm}^{-2}$ and $18.6 \mathrm{kA} \cdot \mathrm{mm}^{-2}$, the similar morphology, as shown in Fig. 1(b), is obtained. It can be found that the original elongated $\alpha$ grains are refined to lots of needle-like grains, implying that the samples undergo a phase transformation during ECP treatment.

Figure 2 presents SEM-BSE images of the distribution of lead inclusion in the samples treated under different current density. Through the determination of EDS, it is known that white dots and grey matrix are lead inclusions and $\mathrm{Cu}-\mathrm{Zn}$ matrix, respectively. Moreover, the morphology of lead inclusions in the sample treated at low current density $\left(18.0 \mathrm{kA} \cdot \mathrm{mm}^{-2}\right)$ is similar to that in the original one (Fig. 2(a)), even $\alpha$ grains are refined to lots of needle-like grains (Fig. 2(b)). Fortunately, as shown in Fig. 2(c), the coarse and random distributed lead inclusions transferred into grain boundaries or defects in dispersed small particles when the sample treated under a critical current density 

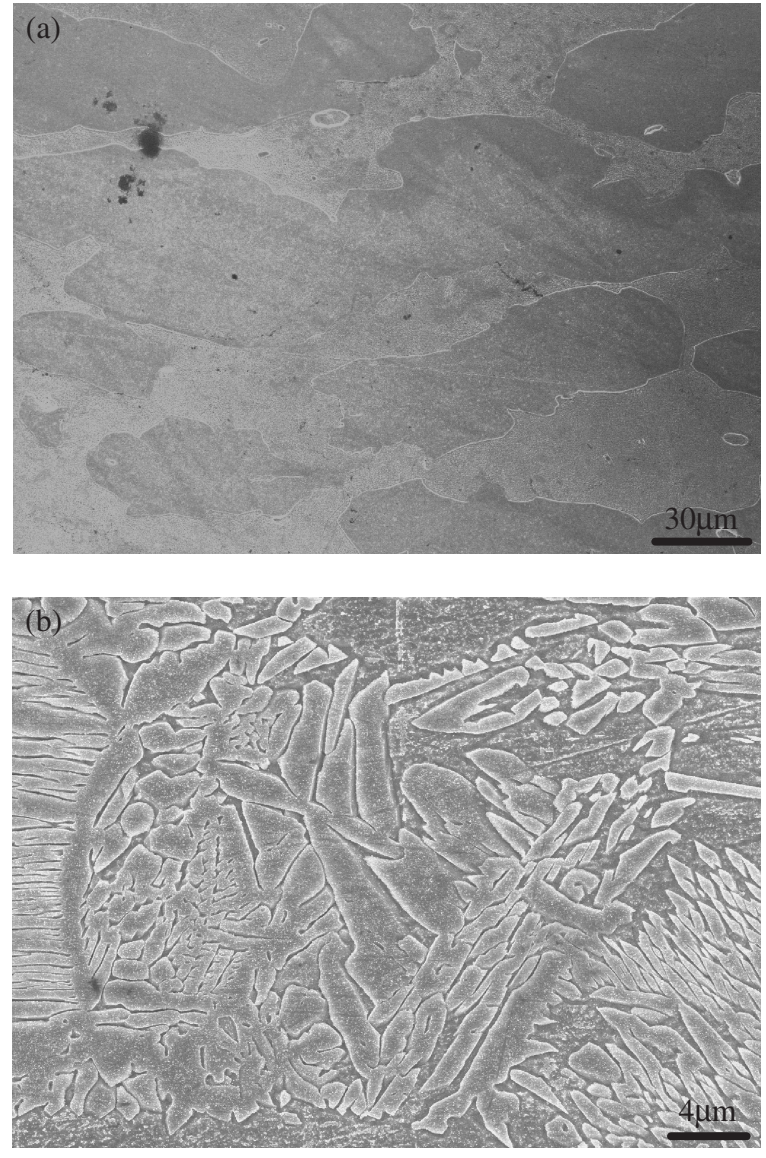

Fig. 1 SEM micrographs of the $\mathrm{Cu}-\mathrm{Zn}$ alloys (a) before ECP treatment, and (b) after ECP treatment.

$\left(18.6 \mathrm{kA} \cdot \mathrm{mm}^{-2}\right)$. However, when the current density slightly higher than the critical one, the sample is melted and broken, and lead distributes along grain boundaries, as the cross section image shown in Fig. 2(d).

\section{Discussion}

Obviously, the temperature rise induced by Joule heat increases with the increase of current density. ${ }^{10)}$ According to the detected waveforms of ECP, the maximum temperature rise of samples treated at $18.0 \mathrm{kA} \cdot \mathrm{mm}^{-2}, 18.6 \mathrm{kA} \cdot \mathrm{mm}^{-2}$, and $19.0 \mathrm{kA} \cdot \mathrm{mm}^{-2}$ can be calculated as $973 \mathrm{~K}, 1023 \mathrm{~K}$ and $1053 \mathrm{~K}$, respectively. They are over the phase transformation temperature of the $\mathrm{Cu}-\mathrm{Zn}$ alloy, ${ }^{11)}$ and as a consequent, $\alpha$ grains are refined to needle-like grains.

As discussed in Ref. 12), the free energy change $(\Delta U)$ in $\mathrm{Cu}-\mathrm{Zn}$ alloy matrix with or without inclusions has some difference due to the deformation of the current lines once a current pass through, and that with inclusions can be written as $\Delta U=\Delta U_{0}+\Delta U_{\mathrm{e}}$, where $\Delta U_{0}$ is the change of free energy in a current-free system, $\Delta U_{\mathrm{e}}$ an energy change due to the change of distribution of current. On the other hand, $\Delta U_{\mathrm{e}}$ takes the following expression generally ${ }^{13-15)}$

$$
\Delta U_{\mathrm{e}}=\mu g \xi V j^{2}
$$

where $\mu$ is the magnetic susceptibility equaling to that in vacuum $\left(\mu_{0}\right)$ in present work; $g$ a geometric factor; $V$ the volume of an inclusion, and $j$ the current density. $\xi$ a factor
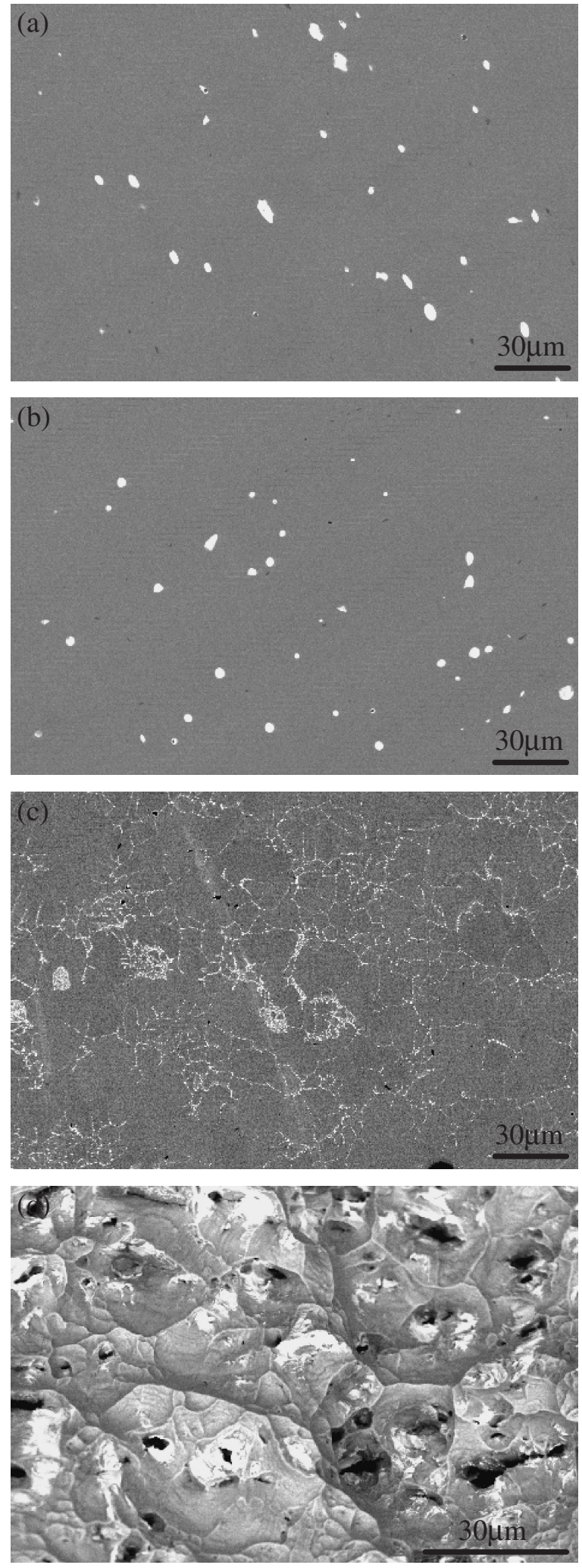

Fig. 2 SEM-BSE images of the distribution of lead inclusion in the samples treated under different current density (a) the original one, (b) $18.0 \mathrm{kA} \cdot \mathrm{mm}^{-2}$, (c) $18.6 \mathrm{kA} \cdot \mathrm{mm}^{-2}$ and (d) $19.0 \mathrm{kA} \cdot \mathrm{mm}^{-2}$.

depending on the electrical conductivities of the matrix and the inclusion, $\xi=\left(\sigma_{\mathrm{br}}-\sigma_{\mathrm{Pb}}\right) /\left(\sigma_{\mathrm{Pb}}+2 \sigma_{\mathrm{br}}\right)$, where the subscripts br and $\mathrm{Pb}$ represent the $\mathrm{Cu}-\mathrm{Zn}$ alloy and lead, respectively. From eq. (1), it is apparent that the sign of $\Delta U_{\mathrm{e}}$ is dominated only by the sign of $\xi$. Since the maximum 


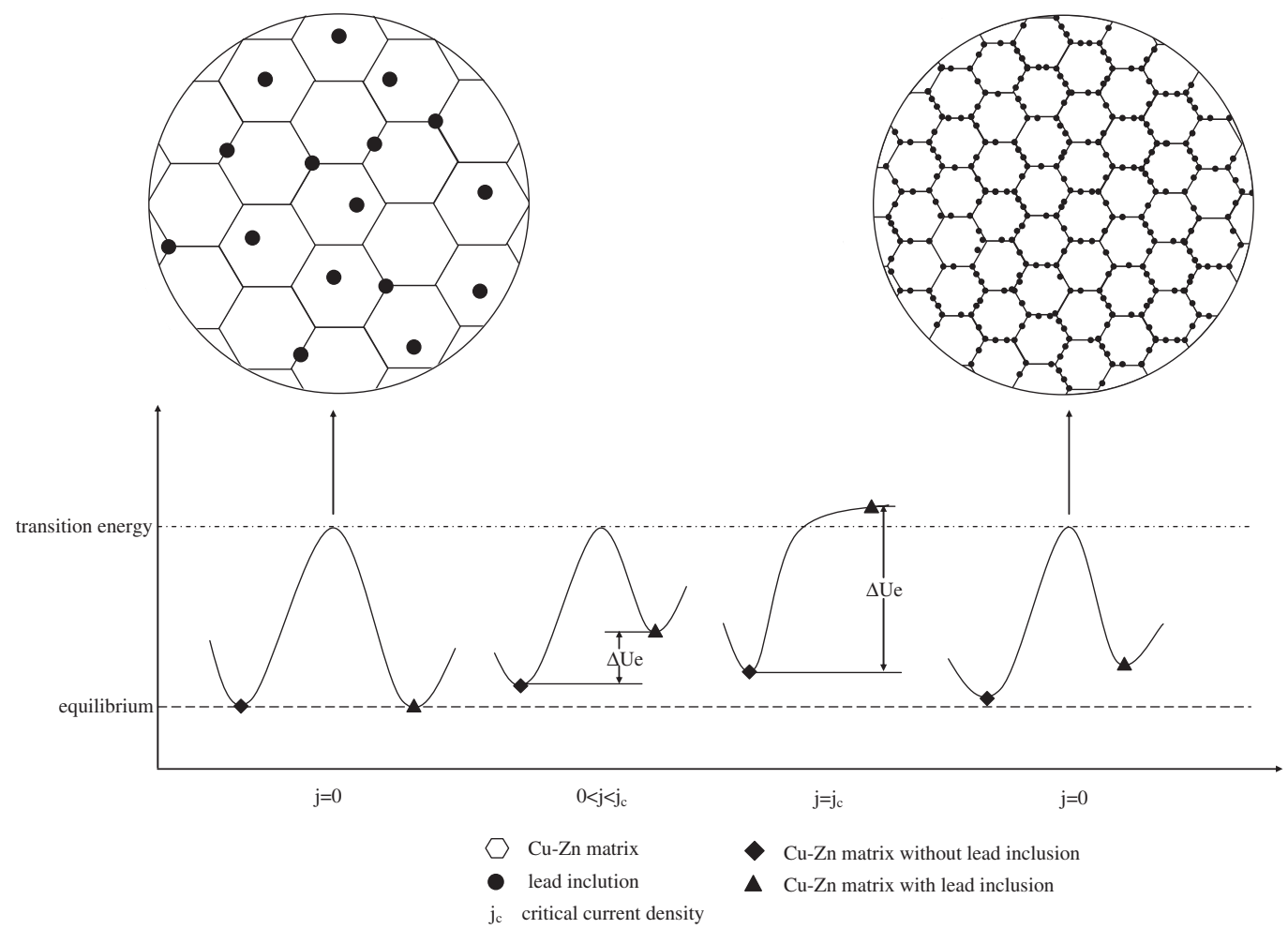

Fig. 3 The energy distribution of the system under ECP treatment.

temperature rise of the sample treated under the critical current density is $1023 \mathrm{~K}$, and $\sigma_{\mathrm{br}}$ and $\sigma_{\mathrm{Pb}}$ at melting point of lead $(600 \mathrm{~K})$ are $6.69 \times 10^{6} \Omega^{-1} \cdot \mathrm{m}^{-1}$ and $2.15 \times$ $10^{6} \Omega^{-1} \cdot \mathrm{m}^{-1}$, respectively, ${ }^{16)}$ it is expected that $\sigma_{\mathrm{br}}>\sigma_{\mathrm{Pb}}$ at $1023 \mathrm{~K}$, and $\xi>0$ and then $\Delta U_{\mathrm{e}}>0$. That is to say, the free energy of the matrix with the lead inclusion is higher than that of the matrix without inclusion once a current passing through. Hence, the energy distribution of the system under ECP treatment can be schematically shown in Fig. 3. With the increase of current density, the free energy difference is enlarged until the lead inclusion becomes unstable at a certain critical value. Because of the rapid cooling course, the unstable solid state at such a high temperature is held to the ambient temperature.

On the other hand, by comparing the distribution of lead inclusions before and after ECP treatment, the average diffusion distance of lead in ECP duration of $800 \mu$ s can be evaluated as half of the average distance of $5 \mu \mathrm{m}$. Therefore, the average atomic drift velocity of lead is about $10^{3} \mu \mathrm{m} \cdot \mathrm{s}^{-1}$. In general, the diffusion of atoms during ECP treatment is mainly controlled by three factors: temperature gradient, concentration gradient, and electric current effect. Hereinto, the temperature gradient between the matrix with lead inclusion and that without vanishes immediately during current passing. That's to say, temperature gradient is not the main factor for the diffusion of atoms.

Then, concentration gradient might be the reason and the average atomic drift velocity controlled by concentration gradient can be calculated as follows:

$$
v_{\mathrm{c}}=\frac{D_{\mathrm{c}}}{X_{\mathrm{c}}} \frac{\Delta X_{\mathrm{c}}}{\Delta x}
$$

Where $X_{\mathrm{c}}$ is the lead content in $\mathrm{Cu}-\mathrm{Zn}$ alloy $(0.3 \%) ; \Delta X_{\mathrm{c}}$ is the change of molar quantity of lead (assumed as $100 \%$ ); $\Delta x$ is the diffusion distance $(5 \mu \mathrm{m}) ; D_{\mathrm{c}}$ is the diffusivity can be calculated by $D_{\mathrm{c}}=D_{0} \exp (-Q / R T),{ }^{17)}$ where $T$ is the absolute temperature, $D_{0}$ the pre-exponential factor, and $Q$ the activation energy. In terms of the pre-exponential factor and the diffusion activation energy of lead in copper, $D_{0}=0.862 \mathrm{~cm}^{2} \cdot \mathrm{s}^{-1}, \quad Q=1.89 \pm 0.01 \mathrm{eV}$. Hence, $v_{\mathrm{c}}$ in eq. (2) is only as low as $10^{0} \mu \mathrm{m} \cdot \mathrm{s}^{-1}$, and it is far lower than $10^{3} \mu \mathrm{m} \cdot \mathrm{s}^{-1}$ in our case. So, concentration gradient is not the reason for long-range diffusion during ECP treatment.

So, electric current effect might be the case and the average atomic drift velocity $v_{\text {ie }}$ produced by electric current is given by ${ }^{1,18,19)}$

$$
v_{\text {ie }}=\frac{D_{0}}{k T}|e| Z^{*} j \rho \exp \left(\frac{-Q}{k T}\right)
$$

Where $Z^{*}$ is an effective charge $\left(Z^{*}=47\right),{ }^{1)} e$ the electron charge, $k$ Boltzmann's constant, $\rho$ the resistivity. Hence, in terms of the above $D_{0}$ and the activation energy $Q$ of lead in copper, $v_{\text {ie }}$ in eq. (3) is about $10^{1} \mu \mathrm{m} \cdot \mathrm{s}^{-1}$ and it is two orders of magnitude less than that in present work. Therefore, the special ECP effect on the pre-exponential factor $D_{0}$ and the activation energy $Q$ should be reconsidered. According to the relationship between $D_{0}$ and $Q$ proposed by Zener and Wert, ${ }^{20)}$ if only integrating the positive current density over ECP remaining time, the activation energy $Q$ could be approximately evaluated as $1.17 \mathrm{eV}$ for the case of $v_{\text {ie }}=10^{3} \mu \mathrm{m} \cdot \mathrm{s}^{-1}$, which is much lower than the value of $1.89 \mathrm{eV}$ given under the thermal diffusion. ${ }^{17)}$ In fact, Horvath et al. have found that the self-diffusion coefficient in nanocrystalline $\mathrm{Cu}$ about $10 \mathrm{~nm}$ is as three orders of 
magnitude large as coarse-grained $\mathrm{Cu},{ }^{21)}$ while its diffusion activation energy is comparable with that in surface of $\mathrm{Cu}$. Recently, Zhang et al. have observed that in the coarsegrained $\mathrm{Cu}-\mathrm{Zn}$ alloy subjected to the ECP treatment, ${ }^{5)}$ the nanophase about $11 \mathrm{~nm}$ was formed. Hence, the transfer of coarse lead inclusions into grain boundaries or defects in dispersed small particles is ascribed to the directional electromigration and also the isotropic diffusion of lead. As a result, in the sample with lead inclusions treated under a current density higher than critical value, the local temperature along grain boundaries and defects is much higher, and the sample is melted and broken (Fig. 2(d)).

\section{Conclusion}

In summary, the coarse and randomly distributed inclusions disappear at a critical current density and transfer into grain boundaries or defects, forming many dispersed small particles by the application of ECP treatment. The fast atom diffusion caused by ECP can be ascribed to not only the dramatically reduction of the diffusion activation energy of lead in $\mathrm{Cu}-\mathrm{Zn}$ alloy, but also the considerable acceleration of the lead diffusion in it at a critical current density. Therefore, the ECP treatment may be a new approach to refine the inclusions of materials in future.

\section{Acknowledgement}

The authors are grateful to thank Prof. J. D. Guo and Mr. B. Q. Wang of Institute of Metal Research, Chinese Academy of Sciences for their help in the ECP treatment experiments.

\section{REFERENCES}

1) P. S. Ho and T. Kwok: Rep. Prog. Phys. 52 (1989) 301-348.

2) A. F. Sprecher, S. L. Mannant and H. Conrad: Acta Metall. 34 (1986) 1145-1162.

3) A. K. Misra: Metall. Trans. 16A (1985) 1354-1355.

4) Y. Z. Zhou, W. Zhang, B. Q. Wang, G. H. He and J. D. Guo: J. Mater. Res. 17 (2002) 2105-2111.

5) W. Zhang, M. L. Sui, K. Y. Hu, D. X. Li, X. N. Guo, G. H. He and B. L. Zhou: J. Mater. Res. 15 (2000) 2065-2068.

6) Y. Z. Zhou, W. Zhang, J. D. Guo and G. H. He: Philos. Mag. Let. 84 (2004) 341-348.

7) M. Guttman: Metall. Trans. 8A (1977) 1383-1401.

8) K. T. Aust, A. J. Peat and J. H. Westbrook: Lattice Defects in Quenched Metals, (Academic, New York, 1965) p. 771.

9) R. E. Hanneman and T. R. Anthony: Acta Metall. 17 (1969) 11331140 .

10) H. Conrad and A. F. Sprecher: Dislocations in Solids, (Elservier, Amsterdam, 1989) p. 499.

11) T. B. Massalski, H. Okamoto, P. R. Subramanian and L. Kacprzak: Binary Alloy Phase Diagrams, 2nd ed., (ASM, OH, 1990) p. 1508.

12) Y. Dolinsky and T. Elperin: Mater. Sci. Eng. A 287 (2000) 219-226.

13) Y. Dolinsky and T. Elperin: Phys. Rev. B 47 (1993) 14778-14785.

14) Y. Dolinsky and T. Elperin: Phys. Rev. B 62 (2000) 12656-12659.

15) R. S. Qin, H. C. Yan, G. H. He and B. L. Zhou: Chin. J. Mater. Res. 9 (1995) 219-222.

16) R. C. Weast, S. M. Selby and C. S. Hodgman: Handbook of Chemistry and Physics, (CRC, FL, 1964) p. 46.

17) E. A. Brandes: Smithells Metals Reference Book, (Butterworth, Washington DC, 1983) pp. 13-17.

18) I. A. Blech: J. Appl. Phys. 47 (1976) 1203-1208.

19) H. B. Huntington and A. R. Grone: J. Phys. Chem. Solids 20 (1961) 76-87.

20) C. Wert and C. Zener: Phys. Rev. 76 (1949) 1169-1175.

21) J. Horvath, R. Birringer and H. Gleiter: Solid State Comm. 62 (1987) 319-322. 